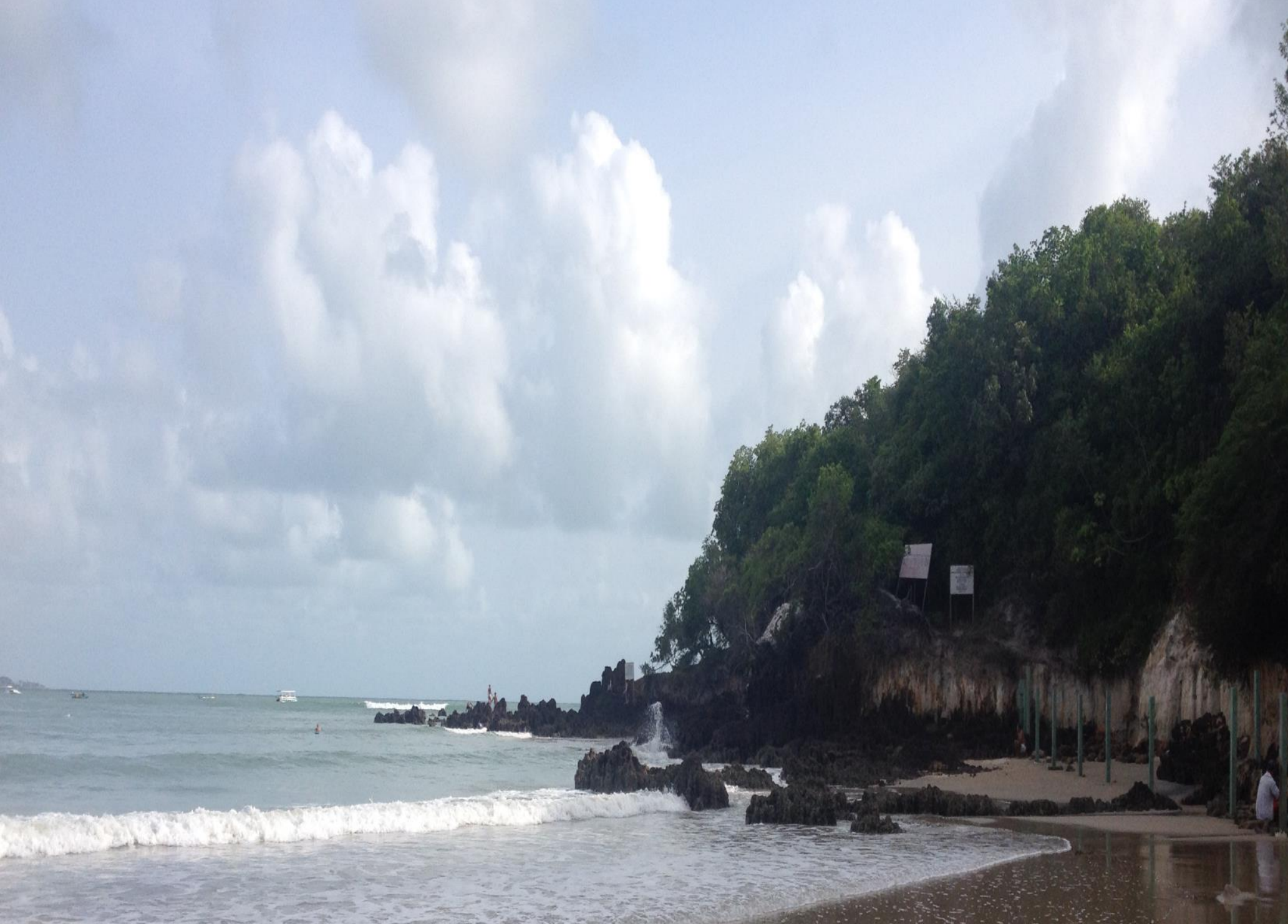

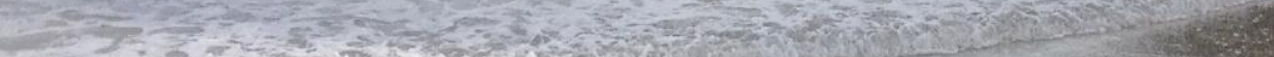

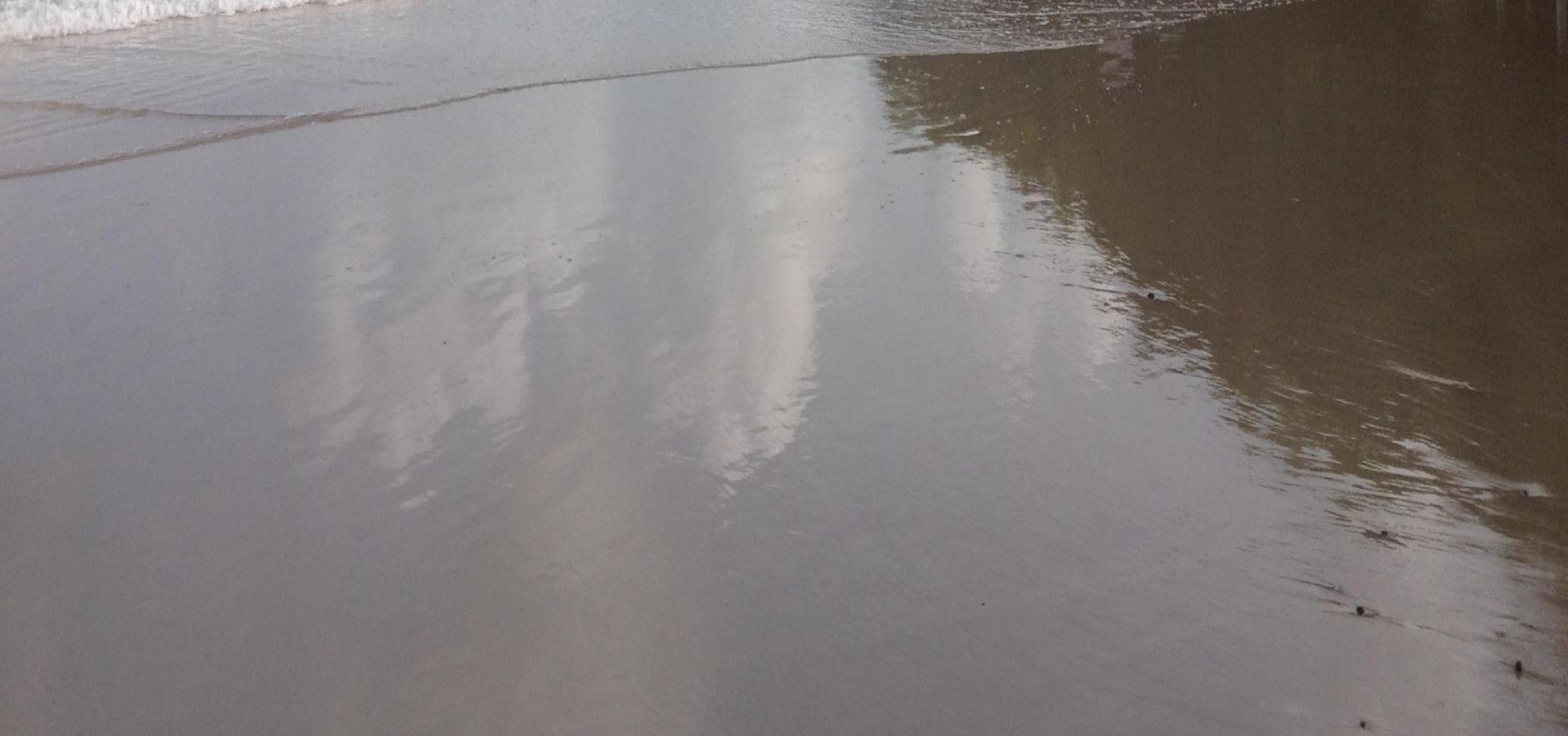




\title{
ESTUDO BIBLIOGRÁFICO DO TURISMO E DOS MUSEUS NA CONFORMAÇÃO DE PAISAGENS CULTURAIS
}

\author{
Bibliographical study of tourism and museums in the conformation of cultural landscapes
}

Marina Marins Morettoni ${ }^{1}$

Resumo: O presente trabalho se caracteriza como uma revisão bibliográfica de caráter qualitativo. Parte da percepção de que a paisagem cultural vem ganhando visibilidade nos estudos do turismo e dos museus, no cenário nacional e internacional. Deste modo, o estudo visa compreender as diferentes abordagens e metodologias utilizadas em pesquisas que se localizam na interseção entre o turismo, os museus e a paisagem cultural. Para tal foram levantados um total de dez artigos - nas bases Scopus, Web of Science e Spell. A partir da análise dos artigos levantados, percebeu-se que há um consenso na apropriação das paisagens culturais para o desenvolvimento do turismo, onde os museus desempenham o papel de atrativo turístico. Identificouse, também, a ausência de rigor metodológico na maioria das publicações analisadas.

Palavras-Chave: Turismo, Museu, Paisagem Cultural.

Abstract: This paper is characterized as a qualitative bibliographical review. Part of the perception that the Cultural Landscape has gained visibility in studies of tourism and museum, in national and international scenario. The present study aims to understand the different approaches and methodologies used in researches that are located between tourism, museums and cultural landscapes. A total of ten articles were collected for this purpose - on Scopus, Web of Science and Spell. From the analysis of the collected articles It was noticed that there is a consensus about the appropriation of the cultural landscapes for the development of the tourism, where museums play the role of tourist attraction. It was also identified a lack of methodological rigor at the analyzed publications.

Keywords: Tourism, Museum, Cultural Landscape.

\section{INTRODUÇÃO}

A paisagem cultural vem ganhando visibilidade nos estudos do patrimônio no Brasil, sobretudo depois de a cidade do Rio de Janeiro, em 2012, ter sido inscrita na Lista de Patrimônio da Humanidade na UNESCO - Organização das Nações Unidas para a Educação, a Ciência e a Cultura, na categoria Paisagem Cultural. Com a campanha "Rio de Janeiro: Paisagens Culturais Cariocas entre a Montanha e o Mar", o dossiê de candidatura considera que a diversidade de elementos geográficos e

\footnotetext{
${ }^{1}$ Mestranda no Programa de Pós-Graduação em Sociologia (Linha de Pesquisa "Cultura, Território e Mudança Social") da Universidade Federal Fluminense, Niterói, RJ, Brasil. Bacharel em Turismo pela mesma Universidade. $<$ mmorettoni@id.uff.br>.
} 
antropológicos, possibilitou a conformação de paisagens culturais únicas, onde as sociabilidades, assim como a cidade, se estabeleceram na topografia entre o mar e as montanhas.

Em consequência, a cidade se coloca mais atrativa, não apenas por sua beleza natural muitas vezes considerada entre as mais belas cidades do mundo - mas também pelo conjunto de sociabilidades, relações e inter-relações que propicia: uma atmosfera singular ao qual passa a ser atribuído um valor patrimonial de relevância internacional. Um cenário, ainda mais próspero, para o desenvolvimento do turismo, que se coloca como um ator social na composição da paisagem cultural. Nessa dinâmica os museus podem representar um importante papel: em muitos países as instituições museológicas movimentam milhões de visitantes (dentre os quais os turistas) anualmente.

Atrelado a este contexto e ao fenômeno de criação de novos museus no mundo - e que vimos identificando no Rio de Janeiro -, em 2016 o principal evento nacional na área, a Semana Nacional de Museus, em sua 14a edição, teve como proposta para a realização de atividades, seminários, palestra e debates, o tema: "Museus e Paisagens Culturais". Aponta-se que este tema foi eleito, em 2016, pelo Icom - Conselho Internacional de Museus - para o Dia Internacional de Museus e proposto como objeto das publicações da 69a edição da revista Museum International, que prevista para ser publicada nesse mesmo ano, veio à público em novembro de 2017. Ainda nesse contexto, o 50 Congresso Unesco Unitwin - Cultura, Turismo e Desenvolvimento, realizou-se na Universidade de Coimbra em abril daquele ano (2017), tendo como um de seus grupos de trabalho, o GT - Território, Rotas Turísticas e Paisagens Culturais.

Adotando, então, como objeto de nosso interesse, a crescente da categoria paisagens culturais, na atualidade, e a centralidade do turismo e dos museus na transformação refuncionalização, reestruturação e "revitalização" - das cidades, que atribui novos usos e estabelece novas centralidades urbanas, este artigo visa apreender - por meio de levantamento bibliográfico qualitativo - como as dinâmicas entre o turismo e os museus vem sendo estudadas na sua interseção com a paisagem cultural.

Acredita-se que em conformidade com a representatividade que o tema vem apresentando em âmbito nacional e internacional, esta é uma oportunidade profícua para se pensar as complexidades e controvérsias que envolvem o turismo, os museus e a cidade, nas relações e interrelações que promovem a transformação das paisagens culturais.

\section{DO CAMINHO METODOLÓGICO}


O levantamento bibliográfico é um estudo essencialmente qualitativo - o que não exclui a possibilidade de uso de dados quantitativos - e implica um trabalho sistemático (ordenado) sobre um objeto de pesquisa (Lima \& Mioto, 2007). Desse modo, afim de identificar as publicações acerca do turismo, dos museus e das paisagens culturais, seguiu-se os seguintes passos: seleção da base de busca; escolha de palavras-chave; pesquisa nas bases com as palavras-chave selecionadas; leitura dos resumos dos artigos e seleção dos textos a serem lidos integralmente; leitura dos textos e análise.

Como ferramenta de pesquisa utilizaram-se as bases Web of Science e Scopus - ferramentas de busca que congregam os principais periódicos e publicações no âmbito internacional -, e Spell para publicações nacionais no campo do turismo. Como palavras-chave em português, inglês e espanhol, selecionaram-se: turismo, museu e paisagem cultural. A busca realizada contou com o uso do conector AND - tourism AND museum AND "cultural landscape", por exemplo - indicando que as publicações devem conter as três palavras pesquisadas em um mesmo documento. Foram retornados oito artigos pela Web of Science, 16 pela Scopus e 14 pela Spell. As buscas em espanhol não retornaram nenhum artigo nas bases.

A partir da leitura do resumo das publicações encontradas, foram identificados 18 artigos que dialogam com o objetivo da pesquisa: cinco na Web of Sciense, oito na Scopus e cinco na Spell. Contudo, algumas limitações de pesquisa foram encontradas: nem todos os artigos tinham acesso permitido ao texto completo; alguns foram encontrados em mais de uma base, se repetindo na Web of Science e na Scopus; e um artigo redigido em mandarim não pôde ser considerado por barreira linguística. Desse modo, foram levantados um total de 10 artigos para a revisão bibliográfica.

A partir da leitura das publicações identificou-se as abordagens metodológicas utilizadas e o tratamento do tema, como exposto a seguir. Por último são listadas as referências bibliográficas.

\section{ATORES SOCIAIS E OBJETOS DA PAISAGEM CULTURAL: UM OLHAR SOBRE O TURISMO E OS MUSEUS}

A paisagem cultural congrega os elementos da geografia física aos elementos materiais e imateriais da cultura - é composta pelas relações e inter-relações entre o homem e o espaço vivido. Enquanto um espaço de encontro entre a natureza e a cultura, a paisagem cultural representa as escolhas e mudanças realizadas pelo homem como integrante de uma comunidade cultural. Na sua relação com a paisagem - rural ou urbana - as escolhas e percepções do homem (porque integrante de uma cultura) estão condicionadas por suas vivências, sua história, ideologias, valores e convenções. (Huerta, 2007; Merantzas, 2016). 
Uma vez que o "espaço é definido pelas interações entre locais únicos, o corpo humano experimenta esses locais como uma construção social" (Merantzas, 2016, p. 10), participando ativamente de sua transformação. Conforma-se uma relação entre o capital cultural do indivíduo e a paisagem circundante, no qual estão presentes elementos materiais (visíveis) e imateriais (invisíveis), tais como os elementos físicos da paisagem natural e artificial - como a arquitetura -, a vida cotidiana das pessoas, os comportamentos sociais, as vestimentas, os sons, os cheiros, e as sensações que o ambiente desperta nos indivíduos. Merantzas (2016, p. 10) ao falar das paisagens culturais da região de Tzoumerka, em Epiros, na Grécia, aponta que "onde objetos inertes existem, um capital cultural estruturado em um corpo de conhecimento é apreciado".

Essa atmosfera que se dá no interstício entre a cultura e o ambiente, se coloca - como indica a maioria das publicações levantadas - como um espaço propício para o desenvolvimento do turismo, que muitas vezes é vislumbrado como uma oportunidade para o desenvolvimento local, especialmente, em cenário de dificuldades econômicas (Meskell \& Scheermeyer, 2008; Corsane, 2016; Lund \& Jóhannesson, 2016). Huerta (2007) considera que "é a partir da Paisagem Cultural, conformada pelo ambiente natural e artificial por meio dos fatos urbanísticos e arquitetônicos, que se geram as bases para o desenvolvimento do turismo com sua criação de riquezas" (p. 130).

A relevância do turismo como atividade econômica é um aspecto que se destaca nas diferentes bibliografias estudadas, em que, muitas vezes, o tema da paisagem cultural aparece como pano de fundo para o desenvolvimento da atividade, imbricada por interesses sociopolíticos e controvérsias no âmbito sociocultural. Desse modo, o patrimônio material e imaterial representaria um recurso cultural a ser apropriado e transformado visando ao desenvolvimento do turismo. Esta percepção é exemplificada por Mason (2009) em seu estudo sobre a representação das comunidades indígenas em Banff, Alberta, Canadá.

Para Huerta (2007), as contradições no uso do patrimônio respondem às ações e interesses de três atores sociais distintos: a iniciativa privada, o Estado e os movimentos sociais. De modo que a iniciativa privada tende a atuar em prol de seus próprios interesses, podendo desencadear impactos muito negativos em ocasiões onde não haja políticas públicas direcionadas à proteção e socialização dos bens patrimoniais - dentre os quais a destruição do entorno ecológico, a "falsificação" do meio urbano e a perda da cultura local. Para esta autora, o Estado tende a operar de forma ambivalente, estando de um lado controlando os usos do patrimônio para a sua preservação, e de outro lado, usufruindo do prestígio do patrimônio para se legitimar; por fim, os movimentos sociais, segundo Huerta (2007), se apropriam do patrimônio cultural como discurso retórico. 
Pensando a apropriação do patrimônio natural e cultural - enquanto paisagem - pelo e para o turismo, a autora pondera que:

O turismo tal como em outras indústrias - muda as paisagens naturais e urbanas, gera impactos e pode contaminar e transformar mesmo quando pretende "conservar" -, está intervindo nas paisagens, as vezes drasticamente, induzindo a uma gestão da natureza e/ou da cultura para a fruição dos visitantes. (Huerta, 2007, p. 124-125)

A percepção do turismo como um fator de desenvolvimento econômico, parece ser um consenso na bibliografia estudada. Nesse cenário, os museus são entendidos, por seu valor patrimonial, como atrativos turísticos. Segundo Godoy (2013), as instituições museológicas "têm-se revelado como fontes potenciais de emprego e de renda para a economia, o que fortalece o turismo. Assim, cada vez mais, compõem um quadro favorável e rentável ao seu desenvolvimento" (Godoy, 2016, p. 41).

A cidade de Ouro Preto, em Minas Gerais, Brasil, pode ser considerada um importante exemplo da atratividade dos museus como atrativo turístico. De acordo com Brusadin (2014), a cidade elevada à categoria de Monumento Nacional em 1933, "é hoje monumento e museu", também chancelada por sua inscrição na Lista de Patrimônio Mundial da UNESCO. Atualmente, representa um dos principais destinos turísticos do país, de modo que para alguns autores, após a transferência da capital do Estado de Minas Gerais para Belo Horizonte, "não fosse a atividade turística, cidades como Ouro Preto poderiam estar vivendo situações piores do que aquelas que hoje vemos como negativas em consequência de um turismo pouco planejado" (Brusadin, 2014, p. 303).

Ainda com vistas de desenvolvimento econômico, outros exemplos surgem nas bibliografias estudadas. A criação do Theodoros Papagiannis' Museum of Contemporary Art representou uma oportunidade de diversificação econômica, em uma região marcada por uma geografia árida e uma sociedade com baixa taxa de natalidade e onde os jovens migram para outras cidades em busca de melhores oportunidades. Tem-se uma iniciativa inovadora em que um museu é instalado em uma escola primária em funcionamento. Seu local de instalação estende-se do horizonte econômico para um investimento no desenvolvimento cultural local. De acordo com Merantzas (2016):

Esta iniciativa tomada em tempos de crise financeira reflete os esforços investidos no desenvolvimento regional, ainda mais em uma área onde as políticas regionais relacionadas à gestão cultural são praticamente inexistentes. Consequentemente, representa um imenso projeto de crescimento da prosperidade e de desenvolvimento de recursos de criatividade cultural a nível local (King, 2011). [...]transforma uma relação funcional com a região em uma vantagem, tanto no nível nacional como no internacional. Nosso caso é uma parte significativa da base que define o patrimônio cultural da região e poderia contribuir para o desenvolvimento econômico e turístico. (p. 12) 
Este é um exemplo positivo de museus inseridos em processos de reestruturação e refuncionalização dos espaços.

Outra perspectiva apreendida, a partir do levantamento bibliográfico, é a de que para além da dimensão econômica do turismo, a criação de novos museus nos espaços urbanos pode estar associada com a disseminação de narrativas nacionais - um discurso oficial - que atua como formador de identidades individuais e coletivas. A caráter de exemplo pode-se citar o Museu da Inconfidência (MI), objeto de pesquisa de Brusadin (2014), e o estudo realizado por Meskell e Scheermeyer (2008) acerca da proliferação de espaços culturais na África do Sul pós apartheid.

No primeiro caso, a conformação do museu se dá em um sítio elevado à categoria de Patrimônio Mundial, cercado por uma paisagem cultural única - a cidade de Ouro Preto, antiga Villa Rica, que teve papel de destaque na Ciclo de Ouro no Brasil e hoje é representação da arquitetura barroca brasileira. Brusadin (2014) comenta que a cidade é em si um museu.

Contudo, o Museu da Inconfidência, em especial, apresenta conflitos com a comunidade local, originados já no momento de sua criação. $\mathrm{O}$ autor pondera que o $\mathrm{Ml}$, assim como muitos outros patrimônios da cidade de Ouro Preto, foi criado com o intuito de sustentação de um discurso nacionalista, durante o Governo de Getúlio Vargas, compondo referências fora do chão, que pouco se relacionam com os contextos histórico, antropológicos e sociológicos da cidade. A criação do Museu da Inconfidência se deu em um contexto de

interesse deliberado do governo Vargas numa política para o turismo, ampliando a possibilidade de atrativos com a oferta do patrimônio histórico nacional. Esta afirmação pode ser verificada na abertura do Museu da Inconfidência em 11 de agosto de 1944 no local da Casa de Câmara de Ouro Preto e, posteriormente, no empenho e investimento oficial no Grande Hotel, edificado naquela cidade. (Brusadin, 2014, p. 303)

Contudo a implementação do museu não teve a participação da comunidade local, que pouco se identifica com suas representações e narrativas.

Com relação ao governo democrático da África do Sul, Meskell e Scheermeyer (2008) consideram que a conformação de uma narrativa nacional está relacionada a construção de um sentido de nação. Diferentemente dos episódios de vandalismo do patrimônio, característicos de modelos de governo em transição, e que marcam a relação memória-esquecimento, na África do Sul os lugares de memória dos regimes de opressão permanecem preservados e conservados. Os autores indicam uma representação da identidade nacional que os governos pós apartheid intentam construir: a anistia, o perdão e o desejo de seguir em frente como nação: uma nação que lutou pela liberdade e pela humanidade. Contudo, a projeção do discurso nacional se sobrepõe a uma polifonia de vozes e não dá espaço à outras formas de representação da história das comunidades sul- 
africanas, desencadeando a formação de movimentos independentes que buscam dar vida e memória à sua própria história (Meskell \& Scheermeyer, 2008).

O principal aspecto controverso nesta relação é a espetacularização e a monumentalidade dos espaços de cultura, muitas vezes, inseridos em regiões em que as condições de vida da comunidade local são precárias. Usualmente, nessas comunidades, como Kiptown estudada pelos autores, os regimes de opressão foram muito intensos. Para Meskell e Scheermeyer (2008), com as iniciativas "pomposas" do governo a atenção com a propriedade terapêutica do patrimônio - no caso, dos museus - nos processos de cura de traumas e memória é substituída pelo interesse na visibilidade da performance nacional. Um cenário que incrementa os conflitos entre os diferentes atores sociais.

Com ressalvas aos impactos negativos do turismo e da inserção de novos objetos no espaço urbano - e cabe considerar que o museu é mais do que um objeto pois é um organismo vivo e dinâmico que se transforma constantemente no seu contato com a sociedade, tal como a cultura e as paisagens culturais - Lund e Jóhannesson (2016), apresentam um interessante estudo sobre a implantação do Museum of Icelandic Sorcy and Witchcraft, localizado no litoral norte da região de Strandir, na Islândia.

O primeiro ponto de interesse está na criação de um museu que surge abertamente como uma proposta de incremento da economia local por meio do desenvolvimento do turismo. Nascido e criado na região, Jón Jónsson elaborou, na década de 1990, um documento que articulava as diferentes possibilidades de turismo como um promotor de desenvolvimento local. Nesse documento estavam compiladas ideias e propostas, extraídas de conversas com moradores da região, referentes as potencialidades turísticas de Strandir. Foi nesse contexto que nasceu o Museum of Icelandic Sorcy and Witchcraft: o diálogo com a comunidade local. Uma proposta de "resgate da história" vivida na região no século XVII (a caça e queima às bruxas).

Outro fator interessante no trabalho de Lund e Scheermeyer (2016), refere-se a maneira como a paisagem cultural está inserida na relação entre o turismo e o museu. Uma dinâmica de mútua dependência onde o museu foi inserido em uma paisagem cultural ressignificando-a e onde a paisagem cultural é indispensável para dar significado ao museu.

Os breves exemplos apresentados, advindos dos artigos estudados neste levantamento bibliográfico, elucidam diferentes formas de relação dos museus e do turismo com a paisagem cultural. Vale ressaltar um aspecto que se sobressai em todos os trabalhos analisados: a inserção de novos objetos e dinâmicas sociais na paisagem cultural está imbricada por interesses econômicos, 
sociais e políticos, onde o turismo, na maioria das vezes, é entendido como um fator de desenvolvimento para as comunidades locais.

A seguir, toma-se as publicações caso a caso, para a melhor compreensão de sua abordagem teórico-empírica, das metodologias utilizadas, bem como os meios de circulação/locais de publicação.

\section{DAS ABORDAGENS E METODOLOGIAS}

Publicado na Revista Brasileira de Pesquisa em Turismo - RBTUR -, o trabalho de Huerta (2007) é o primeiro artigo, na linha temporal deste levantamento, onde o tema da paisagem cultural é apresentado. Trata-se de um ensaio sobre o turismo e os museus em diálogo com as questões da alteridade (o encontro e o estranhamento com o "Outro", o diferente) e da identidade, o reconhecimento do "Eu" nos processos de identificação e diferenciação. A autora, a partir do desencadeamento de ideias, contextualiza o turismo como um fenômeno moderno e a representatividade dos museus como atrativo turístico, dotado de valor estético, simbólico e de uso; onde este último estaria diretamente relacionado a atividade turística.

Segundo Huerta (2007), os museus não apenas expõem aspectos da paisagem cultural, que se fazem presentes nos testemunhos do homem e de sua cultura - no patrimônio - como também compõem a paisagem onde estão inseridos, representando inserções artificiais, de caráter arquitetônico, no espaço. A esse aspecto, a autora acrescenta uma consideração importante: existe uma variedade de museus, para a qual se faz necessário, ao estudar estas instituições, estar atento à proposta, à tipologia, à categoria - museus em edifícios históricos, museus ao ar livre, museus em sítio arqueológico, eco museus, entre outros. A relação com a paisagem cultural se modifica de instituição para instituição.

Gerard Corsane reafirma esta proposição ao estudar a implementação do Robben Island Museum, na África do Sul, e sua elevação a categoria de Sítio de Patrimônio Mundial, na lista da UNESCO, como um dos mais potentes símbolos da liberdade pós apartheid. Em sua publicação na revista Landscape Research, também em 2007, o autor considera que a ilha, ao se tratar de um espaço geográfico específico no qual o museu se articula entre as diferentes paisagens culturais existentes, compartilha características usualmente associadas ao conceito de eco museu. Desse modo, utiliza indicadores qualitativos - que configuram os eco museus - para avaliar a adaptação da ilha à categoria de Patrimônio Mundial e implementação de um museu nacional.

O principal método de pesquisa para a análise foi a observação participante, uma vez que o autor atuou na implementação da Robben Island Museum, como "Robben Island Training 
Programme (RITP) Coordinator" (Corsane, 2007, p. 400). Os indicadores de eco museus - elaborados pelo autor em trabalhos anteriores de revisão de literatura a respeito do "movimento eco museu", da nova museologia e dos "eco museus individuais" -, embora qualitativos, foram utilizados como meio de diminuir a subjetividade na pesquisa, oferecendo um guia com 21 tópicos a serem considerados para análise do autor.

Por meio deste estudo, o autor concluiu que embora o Robben Island Museum não se apresente oficialmente como um eco museu, ele possui todas as características próprias de eco museus, com exceção da participação de trabalhadores voluntários, o que se justifica pelo museu ser autossuficiente. Foram identificadas, também, disputas na relação entre o poder público, a iniciativa privada e a comunidade local na fase inicial de implementação do projeto. Em sua conceituação o museu foi idealizado como um exemplo de novas propostas museológicas ao tratamento do patrimônio na nova África do Sul (democrática), além disso, uma oportunidade de maximizar a economia, o turismo e a educação.

Em Heritage as Therapy - set pieces from New South Africa, publicado no Journal of Material Culture em 2008, Lynn Meskell e Colette Scheermeyer, apresentam uma pesquisa centrada, também, na África do Sul pós apartheid. Os autores estudam o uso do patrimônio cultural para o empoderamento, a restituição ou reparação e a justiça social. Trata-se de um estudo sobre a valorização do patrimônio e criação de espaços de memória, tais como o Apartheid Museum, o Old Fort Museum e o Freedom Park. Carregados de um sentido terapêutico, tais espaços, vem sendo financiados pela iniciativa pública e privada, na busca por promover e sustentar uma ideia de nação: a luta pela humanidade, "anistia, perdão e desejo de seguir em frente como uma nação" (Meskell \& Scheermeyer, 2008, p. 153).

Em um contexto de pressões políticas, táticas de mercado e turismo internacional, os museus se transformam em espetáculos de trauma e memória. Um cenário onde, sob o discurso hegemônico nacional, as vozes dissonantes das comunidades locais são reprimidas; enquanto, se constroem e inauguram edificações monumentais com grande cerimônia, conformando paisagens culturais destinadas, não para a cura da população sul-africana, mas para o desenvolvimento turístico - uma turistificação dos espaços.

Em contrapartida, se organizam à margem alguns grupos com a iniciativa de criar espaços de memória e contar sua própria história, como o Own Town Trust, que organizou uma pequena exposição independente. Para compreender as disputas existentes os autores descrevem os novos espaços de espetáculo na África do Sul e os comparam com as iniciativas de pequena escala que 
surgem por parte das comunidades locais. Não apresentam um detalhamento da metodologia utilizada, mas mencionam o uso de entrevista.

Em Meskell e Scheermeyer (2008) a paisagem cultural é apreendida como um misto entre o ambiente físico e as potencialidades da cultura na sua atratividade turística, compondo espaços propícios à apropriação pelo e para o turismo, onde se instalam atrativos turísticos - que promovem o desenvolvimento econômico e a afirmação de uma narrativa de identidade nacional - tais como os museus. Porém no estudo de Corsane (2007), a paisagem cultural é parte integrante no espaço do eco museu, como um museu fragmentado, ela faz parte dos percursos de visitação. Já Courtney Mason se debruça sobre a apropriação da paisagem cultural, não para a inserção de espaços museológicos, mas para a composição de exposições dentro do espaço do museu.

Em artigo publicado no International Journal of Heritage Studies, em 2009, o autor considera que o Buffalo Nation/Luxton Museum se apropria da paisagem cultural da cidade de Banff, no Canadá, a partir da utilização de imagens de festivais e representação de cerimônias nos displays do museu, apresentando as relações e inter-relações entre os povos indígenas e o espaço da cidade em uma perspectiva espetáculo. Para o autor, esta prática é resultado da atração e entretenimento de turistas com bases no fetichismo do exótico. Esse tipo de exercício reafirma e dissemina um olhar preconceituoso e estereotipado. A pesquisa foi realizada por meio do uso de entrevistas, artigos de jornal e análise das exibições do museu.

A museóloga Karla E. Godoy, em artigo publicado no Caderno Virtual de Turismo, em 2013, se debruça sobre o olhar do turista na sua relação com o Museu Forte Defensor Perpétuo. Alojado em edificações datadas do século XVIII - Ciclo do Ouro - voltadas para a proteção da Baía e do Porto de Paraty, "por onde se escoava toda a produção mineira, na época" (p. 36), o museu conforma diferentes paisagens culturais. Contudo, o artigo se dedica ao estudo da demanda turística do museu, considerando a atratividade da instituição museológica. A paisagem cultural, assim como em outros artigos aqui estudados, não figura entre os objetivos centrais da pesquisa, mas está presente na relação do museu com a cidade enquanto lugar de memória - neste caso a cidade de Paraty tratada na revisão bibliográfica.

O artigo, diferente dos anteriormente apresentados, possui um apartado destinado ao delineamento da metodologia utilizada, onde, primeiro é apresentado os pressupostos empíricos, teóricos e metodológicos da pesquisa. A autora realizou uma pesquisa do tipo survey, com aplicação de questionários em português, espanhol, francês e inglês, com perguntas abertas e fechadas. Apresenta, ainda, um detalhamento do instrumento - questionário - de pesquisa utilizado. Além disso, informa: 
Nos dias e horas agendados, os pesquisadores aplicaram a pesquisa [...] por quatro horas ao dia, em quatro dias distintos, durante dois meses consecutivos, divididos em duas etapas (a primeira em janeiro/fevereiro e a segunda em junho/julho).[...] Posteriormente à pesquisa de campo, as informações dos questionários foram sistematizadas em planilhas e ocorreu a tabulação dos dados. Os dados qualitativos, ou seja, as sugestões, observações, críticas e outras informações obtidas, também foram sistematizados e analisados. (Godoy, 2013, p. 4243).

Nos resultados encontrados, Godoy (2013) destaca que, embora sejam necessárias algumas melhorias (indicadas ao final do artigo) para a qualificação do museu como atrativo turístico, a instituição parece estar atrelada à vida cultural da cidade.

Tal como Godoy, Silva e Pinheiro (2014) apresentam uma seção específica de seu trabalho dedicada a metodologia da pesquisa realizada. $\mathrm{O}$ artigo publicado no Caderno Virtual de Turismo, se configurou como uma pesquisa exploratória com observação in loco - no qual foram tiradas, inclusive, fotos do espaço pesquisado -, adotando como procedimento técnico (como indicam os autores) a coleta de dados e informações em artigos, livros, teses e dissertações, assim como sites de órgãos competentes, tais como o Ministério do Turismo e o Departamento Nacional de Infraestrutura de Transportes. Cabe dizer que a pesquisa se dedica ao estudo do projeto de "revitalização" da Estrada de Ferro Madeira-Mamoré, que objetiva a criação de um espaço de cultura, turismo e lazer para a cidade de Porto Velho - RO.

Após a leitura do artigo considerou-se não o incluir na bibliografia deste levantamento, uma vez que o projeto de "revitalização" de que trata - a Estrada de Ferro Madeira-Mamoré - reificou a extinção do antigo museu da ferrovia, que costumava estar instalado no Armazém 1 do Complexo. Contudo, este representa um exemplo destoante das bibliografias que vem sendo estudadas e de um movimento, que se pretende global, de criação de novos museus. Desse modo, considerou-se relevante, manter esta referência, afim de apresentar o contraponto, no qual, em um projeto de reestruturação e refuncionalização da paisagem urbana, o espaço que antes era destinado a um museu - que de modo geral é apresentado homogeneamente por autores da produção nacional e internacional como importante atrativo turístico - dá lugar a criação de um polo gastronômico.

Outra abordagem interessante é a de Leandro Benedini Brusadin, em publicação no Caderno Virtual de Turismo, que se dedica a estudar as relações entre o Museu da Inconfidência em Ouro Preto $(M G)$ e a comunidade local. O museu representa um atrativo turístico inconteste a nível nacional e internacional, inserido em uma paisagem cultural urbana de valor arquitetônico inestimável. Contudo, embora estabeleça uma relação física constante com a comunidade residente - localizado na Praça Tiradentes: "um local de passagem obrigatório, pois dá acesso a muitos lugares que fazem parte do cotidiano dos habitantes" - o museu, em seu edifício monumental, encontra 
dificuldades na atração desse público (Brusadin, 2014, p.301). Para o autor isso se dá porque, ainda intrinsecamente relacionado com o espaço físico da cidade e sua história, os residentes não se veem representados pelas exposições do museu; considera ainda a existência de conflitos entre os moradores e o MI no uso do espaço da Praça Tiradentes, onde o museu está localizado. Para este estudo o autor se valeu de observação participante e pesquisa documental no Arquivo Administrativo Casa do Pilar e na Biblioteca do Museu da Inconfidência.

O estudo de Katrín Anna Lund e Gunnar Thór Jóhannesson, publicado na revista Cultural Geographies, no último ano (2016), é o que melhor representa o caráter subjetivo das paisagens culturais. Centra-se no "tornar-se" lugar a partir dos encontros promovidos pelo turismo - uma relação marcada pela materialidade de substâncias terrestres da paisagem cultural. Lund e Jóhannesson (2016), apresentam uma pesquisa exploratória - ao qual eles consideram estudo de caso - do Museum of Icelandic Sorcery and Witchcraft, na região de Strandir, costa norte da Islândia.

A perspectiva apresentada, considera que no lugar do turismo as conexões extrapolam a relação entre natureza e cultura, passado e presente - como no caso do Museum of Icelandic Sorcery and Wictchcraft, onde os agentes humanos e não humanos (como por exemplo o vento, a neve e, no caso específico, o místico) se colocam como imanentes da vida e das relações entre o homem e o ambiente.

No texto, os autores consideram que a "'a poética do fazer' [...] a criatividade que engloba o emaranhamento entre o humano e o não humano" possibilita tecer inúmeras substâncias que trazem à tona as tensões entre a presença e a ausência. Essa dinâmica cria um entre lugar - "uma figura em branco, um elemento de ordenação que abre novas possibilidades para conectar uma variedade de elementos e substâncias" (Lund \& Jóhannsson, 2016, p. 654).

Na concepção dos autores, o museu, criado com o objetivo de desenvolver a atividade turística, representa uma zona de contato, onde diferentes narrativas e combinações de elementos "blank figures" - podem emergir formando a poética do lugar. Atua, dessa maneira, na transformação da paisagem cultural e na imagem da região de Strandir. Instalado em um galpão preto de portas vermelhas e telhado coberto de grama, em diálogo com a paisagem natural do entrono e com o passado local de caça e queima às bruxas no século XVII, compõe uma narrativa mágica e paisagem cultural específica que propicia o desenvolvimento da atividade turística.

Christos Merantzas em seu estudo exploratório sobre o Theodoros Papagiannis' Museum of Contemporary Art, localizado em Tzoumerka, Epirus, na Grécia, também enfatiza o caráter subjetivo da relação entre o homem e o ambiente vivido. No artigo, publicado no Internacional Journal of Culture and History, em 2016, a paisagem cultural, apropriada pelo turismo, se forma e se 
transforma na relação entre o visitante e o espaço. Isso se dá, não só porque o museu, instalado no prédio de uma escola primária, reestruturou e refuncionalizou o espaço, mas também porque extrapola os limites de seu espaço físico para o ambiente natural, com a colocação de esculturas em pedra ao longo de diferentes caminhos que ligam o museu ao Monastery of Tsouka - trilhas turísticas onde o turista pode ressignificar os espaços.

Essa composição, integra uma nova experiência do lugar onde o indivíduo - para Merantzas (2016), o turista - pode atuar ativamente na construção e transformação do lugar enquanto caminha entre os diferentes pontos de interconexão (as estátuas) e descobre os caminhos. Assim como característico das paisagens culturais, o percurso elaborado pelo museu, congrega a sobreposição de tempos e espaços.

Por fim, no artigo de Adalgiso Silveira e Miriam Rejowski, tal qual Godoy (2013) e Brusadin (2014), a paisagem cultural é apresentada enquanto contextualização do espaço onde se desenvolve a atividade turística. A pesquisa exploratório-descritiva, de caráter qualitativo, centra-se no estudo do Chá Imperial no Museu Casa da Era, localizado na região do Vale do Paraíba, um espaço rural característico de fazendas históricas. A paisagem cultural congrega a rusticidade do café e refinamento da elite cafeeira, assim como o surgimento de santuários ecológicos, com a retomada da natureza após a decadência do café. O evento Chá Imperial é tido como objeto de pesquisa dada a sua relevante atratividade turística entre 1988 e 2002 - recorte temporal do estudo. É um estudo de caso, conforme os autores, pautado no acesso à bibliografias e documentos, e na realização de entrevista abertas.

Tendo em vista os textos contemplados por este levantamento, compreende-se que a paisagem cultural enquanto objeto da curiosidade do turismo - como campo de estudo - e dos museus vem se colocando como uma pauta relativamente recente, com publicações, que congregam estes três temas concentradas nos últimos 10 anos.

Neste estudo, os artigos referenciados se colocam temporalmente da seguinte maneira: dois artigos em 2007; um em 2008, 2009 e 2013; dois em 2014; e três em 2016. Dos dez artigos estudados, cinco foram publicados em revistas direcionadas ao estudo do patrimônio, das paisagens culturais ou da geografia cultural, como: Landscape Research, Jornal of Material Culture, Cultural Geographies, International Journal of Heritage Studies e International Journal of Culture and History. Enquanto que os demais artigos, em sua maioria publicações nacionais, foram publicados em revistas específicas para estudos do Turismo, a saber: Caderno Virtual do Turismo, com três publicações; Revista Brasileira de Pesquisa em Turismo; e Revista Rosa dos Ventos. 


\section{CONSIDERAÇÕES FINAIS}

O turismo, como fenômeno social moderno e atividade econômica estruturada, vem assumindo centralidade em dinâmicas de transformação socioespacial: os ditos processos de turistificação. Estes, associados à conformação de novas formas de sociabilidade entre os atores sociais influentes no setor - tais quais o trade turístico, os turistas e excursionistas, os trabalhadores que atuam direta e indiretamente, formal e informalmente, o governo, a comunidade local -, transformam as paisagens culturais das cidades. $\mathrm{O}$ turismo representa, dessa maneira, um horizonte de possibilidades, seja no que se refere aos impactos negativos, seja em relação a conformação de um espaço de investimentos, de fortalecimento de identificação nacional, etc. Dentro desta lógica os museus tornam-se relevantes porque são em si o espaço onde o homem se relaciona com sua cultura - lugar aberto aos processos de diferenciação e identificação - mas também porque representam importantes atrativos turísticos: tornam-se objeto meio para um objetivo fim.

Tal perspectiva, que mescla relevância patrimonial à relevância turístico-econômica, se fez presente nos textos aqui apresentados. O levantamento bibliográfico realizado tratou de identificar as abordagens e metodologias utilizadas entre 2007 e 2016, visando compreender o turismo e os museus em sua interseção com a conformação das paisagens culturais. Com base neste estudo, percebeu-se o estabelecimento de um viés hegemônico que norteia a abordagem do tema e sua aplicabilidade prática, onde se sobressai a concepção da paisagem cultural como recurso para o desenvolvimento do turismo, visando ao desenvolvimento econômico das comunidades locais. São poucos os estudos em que a paisagem cultural ganha centralidade, em detrimento do turismo e dos discursos dele decorrentes. Desse modo, compreende-se que as bibliografias publicadas no decorrer de uma década (2007-2016) dão ênfase, sob uma perspectiva crítica, à apropriação e transformação das paisagens culturais para a oferta turística, sobretudo, em cidades e regiões que apresentam "dificuldades" econômicas.

A ênfase na relevância turístico-econômica identificada não representa necessariamente um descolamento entre a teoria e a prática - polaridade certas vezes existente nas publicações de turismo, ora entendido como alavanca para a valorização da cultura e para a geração de divisas, ora pensado como gerador de impactos negativos inquestionáveis, pautados unicamente em interesses econômicos. Espelha, todavia, no âmbito da reflexão acadêmica o que se percebe na dimensão das práticas sociais e políticas, sem apresentar, no entanto, uma reflexão profunda acerca do processo de transformação das cidades, da turistificação dos espaços, da criação de novos museus. Percebe-se uma predomina da constatação em detrimento da análise, feito que acompanha a realização de estudos exploratórios, de caráter qualitativo, sem detalhamento ou cuidado na exposição dos 
métodos utilizados; excetuados os trabalhos elaborados por Corsane (2007), Mason (2009) e Godoy (2016), que estudaram o Robben Island Museum, o Buffalo Nation/Luxton Museum e o Museu Forte Defensor Perpétuo, respectivamente.

Tal observação, que assume tom de crítica, não se direciona ao uso de metodologias propriamente qualitativas, mas sim à ausência de maior rigor metodológico na realização das pesquisas. O presente artigo baseia-se ele mesmo em um recorte qualitativo do estudo dos museus, do turismo e das paisagens culturais. Em se tratando de levantamento bibliográfico, o detalhamento do passo a passo realizado faz-se essencial, bem como a indicação das dificuldades encontradas, a saber: a impossibilidade de acesso de alguns materiais e barreira linguística para leitura de artigo publicado em mandarim; no entanto, é um exercício de pesquisa basilar, que possibilita a melhor apreensão do tema, assim como as abordagens utilizadas, indica também a necessidade de novos e aprofundados estudos.

A deficiência identificada quanto ao rigor metodológico predominante nas bibliografias estudadas aponta para uma instigante possibilidade: o aprofundamento da análise em relação à prática. Neste sentido, parece profícuo o mapeamento das controvérsias, dos ruídos, da polissemia das vozes dos atores sociais atuantes e que falam ao mesmo tempo. Aponta para a necessidade de esmiuçar as práticas sociais e políticas que envolvem a criação dos novos museus nas cidades e em que medida elas incentivam ou limitam a turistificação dos lugares. Para tal, prescinde compreender o turismo e os museus como fenômenos modernos complexos que se encontram - tal qual as paisagens culturais (dinâmicas) - diretamente relacionados com a sociedade e com as cidades onde se estabelecem, estando em constante transformação. Para tal, considera-se que esmiuçar um recorte sócio-histórico das paisagens culturais (turistificadas) pode ser proveitoso a este fim.

\section{REFERÊNCIAS}

Brusadin, L. B. (2014). O Museu da Inconfidência em Ouro Preto (MG) e sua interface com o turismo, o patrimônio e a comunidade local. Caderno Virtual de Turismo. Rio de Janeiro. v. 2014, n 3, p. 298315.

Corsane, G. (2006). Using ecomuseum indicators to evaluate the Robson Island Museum and World Heritage Site. Landscape Research. v. 31, n. 4, p. 399-418.

Godoy, K. E. (2013). Fortificações como atrativo turístico: um estudo sobre o Museu Forte Defensor Perpétuo, em Paraty (RJ). Caderno Virtual de Turismo. Edição Especial: Turismo em Fortificações. Rio de Janeiro. v. $1, \quad$ n. 1, 2013. p. 34-48. Disponível em: <http://www.ivt.coppe.ufrj.br/caderno/index.php/caderno/article/view/854/373>. 
Huerta, T. S. (2007). Turismo y patrimonio: otredad e identidad. Revista Brasileira de Pesquisa em Turismo. v. 1, n.1, 2007. p. 110-135. Disponível em: < https://rbtur.org.br/rbtur/article/view/81/80>.

Lima, T. C. S. \& Mioto, R. C. T. (2007). Procedimentos metodológicos na construção do conhecimento científico: a pesquisa bibliográfica. Revista Katál. Florianópolis, v.10, n. eps., p. 37-45. Disponível em: $<$ http://www.scielo.br/scielo.php?script=sci_abstract\&pid=S1414$49802007000300004 \& \operatorname{lng}=e n \& n r m=i s o \& t \operatorname{lng}=p t>$.

Latour, B. (2000). Ciência em ação: como seguir cientistas e engenheiros sociedade afora. Editora UNESP: São Paulo.

Lund, K. A. \& Jóhannesson, G. T. (2016). Earthly substances and narrative encounters: poetics of making a tourism destination. Cultural Geographies. v. 23, n. 4, p. 653-669.

Mason, C. W. (2009). The Buffalo Nations/Luxton Museum: tourism, regional forces and problematizing cultural representations of aboriginal peoples in Baff, Canada. International Journal of Heritage Studies. v. 15, n. 4, pp. 355-373.

Merantzas, C. (2016). Assessing local cultural heritage through a walking trail: the case study of the Teheodoros Papagiannis' Museum of Contemporary Art. International Journal of Culture and History. v. 3, n. 2, p. 9-27.

Meskell, L. \& Scheermeyer, C. (2008). Heritage as therapy: set pieces from the New South Africa. Journal of Material Culture. v. 13, n. 2, p. 153-173. Disponível em: <http://journals.sagepub.com.ez24.periodicos.capes.gov.br/doi/pdf/10.1177/1359183508090899>.

Silva, J. L G. \& Pinheiro, J. A. (2014). Análise do projeto de revitalização do patrimônio histórico da estrada de ferro Madeira-Mamoré. Caderno Virtual de Turismo. Rio de Janeiro. v. 14, n. 2, 2014. p. 167-182. Disponível em: <http://www.ivt.coppe.ufrj.br/caderno/index.php/caderno/article/view/840/397>.

Rejowski, M. \& Silveira, A. S. (2016). Turismo Cultural e Patrimônio: o chá imperial no Museu Casa da Era. Revista Rosa dos Ventos - Turismo e Hospitalidade. v. 8 (IV). pp. 1-13. Disponível em: <http://www.ucs.br/etc/revistas/index.php/rosadosventos/article/view/4616/pdf>. 